\title{
EL HORIZONTE LINGÜÍSTICO \\ (Presentación de la Revista Língua, Lingüística e Literatura)
}

\author{
ANTONIO DOMÍNGUEZ REY \\ UNED. Madrid \\ adominguez@flog.uned.es
}

\section{RESUMEN}

Esta Nota pretende ser la presentación de una nueva Revista brasileña de Lengua, Lingüistica y Literatura, tres «L» que forman y fundamentan el nudo del conocimiento, la fuente cognitiva del hombre en el mundo. El conjunto va acompañado de una revisión crítica de los fundamentos clásicos y modemos de los estudios gramaticales y literarios.

Palabras Clave: Nueva Revista: Filología: Brasil. Habla, texto, escritura, lingüistica cognitiva. significante.

\section{RÉSUMÉ}

On présente içi une nouvelle revue brésilienne de Langue, Linguistique et Littérature, trois «L» qui font et fondent le noeud de la connaissance, la source cognitive de l'homme au monde. L'ensemble s'accompagne d'un compte rendu critique en partant des fondements classiques et modernes des études grammaticales et litteraires.

Mots-CLEF: Nouvelle Revue; Philologie; Brésil. Parole, texte, écriture, linguistique cognitive, signifiant.

La publicación de una nueva revista de pensamiento y análisis del lenguaje siempre alegra al mundo humanístico de la creación verbal. Se trata en este caso de una publicación brasileña de Língua, Lingüística e Literatura, editada por el Departamento de Letras Clásicas y Vernáculas de la Universidad Federal de Paraíba*.

* Língua, Lingüistica e Literatura, Vol. 1, n. 1, 2003 / João Pessoa, 2003, Paraíba (Brasil). 
Pudiera parecer redundante que rodeen el campo de la Lingüística con Lengua y Literatura, pero no lo es, porque la ciencia del lenguaje preside uno y otro dominio, el idiomático y literario, al tratar la lengua desde principios y fundamentos que, como facultad cognoscitiva, induce en las concreciones prácticas y teóricas de cualquier idioma y textos en ella obrados. El lenguaje, objeto científico de la Lingüística, comprende la estructura, producción y análisis de lengua, habla y literatura, sea ésta una obra específica o una teoría general del texto literario.

Y así lo entiende el consejo de la revista al incluir en el primer número textos teóricos concernientes al lenguaje, al aprendizaje y adquisición de la lengua, su aplicación en sectores concretos, sobre todo en escuelas, y al análisis textual, desde el estrictamente literario al publicista. Atiende además a una división tan famosa como controvertida desde F. de Saussure a esta parte, el enfoque diacrónico y sincrónico de la lengua y su producción literaria. Así tenemos trabajos sobre teoría de géneros; sobre la gramática griega de D. de Tracia; sobre un poema de C. Drummond de Andrade; la vanguardia; el espacio de escucha y las relaciones interpersonales en la infancia preescolar; la lengua gótica; la semasiología de espacios mentales poéticos en $O$. Bilac, también poeta brasileño, parnasiano; una cantiga curiosa, ya prebarroca, de Gil Pérez Conde; cuestiones cognitivas o de interacción sociolinguística del saber humano; «Zeus na Orestéia», la estructura del dios de dioses, el rostro siempre último, diríamos, de las diversas figuras que sus atributos representan con otros nombres también divinos; la evocación de estudios culturales en la obra de Ademar Vidal; un artículo selecto sobre las nociones de sujeto y sentido en el lenguaje; el estatuto del manhês en la adquisición del idioma; una relectura del objeto antes aludido de la linguística en F. de Saussure; relaciones literarias con la historia y la memoria cultural y, por último, el interdiscurso de la interpretación textual en la propaganda turística y en el sertão.

A decir verdad, todos estos temas entrarían en el campo propio de la Lingüística si atendiéramos a factores implícitos de tiempo, espacio, modo y relación intríseca e interaccionada de elementos, en una palabra, a la Sinnesartikulation del lenguaje, como se hacía ya entre los siglos XIX y xx. Se impone, no obstante, la división del trabajo, pero una clasificación suya razonada sin multiplar inútilmente los entes, como sucede en el primero de los artículos citados, de L. A. Marcuschi: «A questão do suporte dos géneros textuais». Es cierto que la materia signata diferencia la superficie semántica de un enunciado posible al emitirlo de viva voz, por carta, fax o alfabeto codificado. No lo es menos, sin embargo, que tendríamos que considerar también la página en blanco o simplemente emborronada como soporte diferenciado de un escrito según quien sea el que la use, S. Mallarmé, un poeta tachista, «concreto», o el recadero, sobre todo si éste acierta casualmente con un garabato y resulta una obra de arte. Al identificar el género en relación con el soporte, según comenta el autor citado, la materia para ello escogida, añadimos, ya está de algún modo semantizada: la foné semantiké, por ejemplo, de Aristóteles. El emisor ya la textualiza. Y esta consideración nos sitúa ante otro concepto de lengua y lenguaje más ajustado a lo que una verdadera Lingüística debiera ser, pues también la intención comunicativa, y expresiva, ha seleccionado el material fónico -órganos articuladores del aire respirado- como más adecuado y en consonancia con la facultad del lenguaje. El caso del texto escrito con humo en el aire por un avión resulta significativo al respecto: «Parece que a nuvem de fumaça tem as duas funções: materializa e sustenta 
o gênero». ¿Y el aire articulado de las palabras? ¿Es sólo materia, soporte? Solemos interpretar el sonido ya fonologizado lineal y discretamente, segmentado, pero el continuo del habla se percibía antes también como volumen fónico de figura invisible. ¿No tiene volumen el fonema? He ahí una reducción analítica de la materia signata del significante. Juan de Caramuel ya atendía en el siglo XVII a este volumen e imagen fónica del sonido verbal al articularlo y percibirlo.

El significante supone algo más que expresión. Tanto el fono como el grafo, la escritura, que es, según Humboldt, prolongación significante de aquél, son procesos fonologizados del decir. La intención comunicativa transforma el sonido natural de la voz en algo concepto. El género no puede prescindir de la génesis que lo constituye y ésta comprende también la materia que concibe como soporte. La voz humana es instinto natural de una función conceptiva.

Este preámbulo nos sirve de entrada al objeto de la Lingüística según lo trata Saussure y reconsiderado aquí, en la revista que presentamos, por Mónica Nóbrega siguiendo sobre todo los manuscritos del profesor ginebrino editados por R. Godel y S. Bouquet. Una mala lectura del Curso de Lingüística General indujo a excluir parcialmente el habla de la Lingüística considerada como sistema y a tratar la sincronía en contraposición con la diacronía. Delineamos un mapa sin conocer el terreno ni aun a vuelo de pájaro.

El concepto de virtual es decisivo en el funcionamiento del lenguaje, tanto en su constitución morfoléxica como semántica, y el concepto saussureano de valor fue poco atendido por lingüistas posteriores . Funciona siempre con un fondo de potencia y horizonte de actualidad posible, incluso cuando partimos de formas concretas del habla. Hablar supone distanciarse hasta cuando tenemos al interlocutor delante. Pero una distancia peculiar, pues nos adentra en una dimensión de relaciones continuamente alternas, asociadas, yuxtapuestas, implicadas, encastradas, superpuestas, correlacionadas, etc. $\mathrm{Al}$ prescindir de una fundamentación científica del signo en aras de un marco más comprehensivo de la comunicación, como si en aquél no estuviera también codificada la capacidad comunicativa que lo engendra, caben posturas, enfoques, consideraciones que convierten lo accesorio en esencial, los corolarios en tesis, como sucede en muchas escuelas actuales de lingüística.

Mónica Nóbrega resalta la observación de S. Bouquet sobre la estructura virtual del sintagma saussureano en relación con estas escuelas. El sintagma ya liga in absentia items lexicales. Cabe decir, pues, que toda forma verbal se constituye en función de una potencia cuya actuación la despliega radialmente en posiciones posibles de texto que ella ya contempla de algún modo. Tal potencia es el arco virtual de sus actuaciones, y en tal virtus, que es vis verbi, como intuían ya san Agustín y Tomás de Aquino, entra el cauce que la contiene. Su acción acuña el lecho que crea. El sintagma también forma paradigma. $\mathrm{Y}$ ese fondo de relieve en un espacio de fondo siempre abierto entre la presencia de una forma y el halo o huella ausente que la genera no cabe en una linguística lineal sin volumen o sólo transformativa, de reescritura, donde el signo igual de la ecuación o espacio topologico identifica dos procesos muy di-ferentes, antes y después, nunca simétricos, como sucede realmente en el lenguaje.

De ésta u otra consideración depende el acierto científico de la Lingüística al concretar su objeto de estudio. La reducción de su entorno nos lleva a otras tan peligrosas como la que desatiende del acto mental aquella marca fónica del significante concepto. 
Así le acontece a la mal denominada lingüística cognitiva, que extrae una imagen de la reducción previa operada sobre el lenguaje y luego pretende explicar éste con ella. Lo co de la gnosis implica una génesis antecedente, prelativa, que la palabra, el signo, ya aporta como estructura espaciotemporal de la situación que la emerge. No se puede hablar de cognición sin saber cuál es el fondo hermenéutico y fenomenológico de la gnosis. Por eso cuadra mejor la denominación gnoseológica para comprender lo que la linguística cognitiva y pragmática abstraen y quieren luego fundamentar. Confunden la división del trabajo analítico con la científica. Quien conozca el método hermenéutico o el fondo gramatical de tales estudios en Schleiermacher y Dilthey, con precedente filológico en Herder, Hamann, Gerber, Hegel y Nietzsche, hasta llegar al paso de la filología a la lingüística, partiendo del comparatismo, con Amor Ruibal, o a la estructura de la intención significante en Husserl, y del sujeto dicente, con E. Lévinas y Ortega y Gasset, sabe, podemos concluir, que toda forma implica el fondo que la genera y remite al eje ideológico que la engloba. Tendremos que estudiar el modo y alcance de esta implicación y remite. Las inferencias, abducciones, los mapas, diseños cartográficos, matrices morfoléxicas y semánticas, frames, procesos de footing y blending o posición interlocutiva y fusión de espacios mentales, respectivamente, así como las funciones de adquisición, almacenamiento, transformación, transmisión, movimientos en alfa, factores PRO, etc., son meros corolarios de la acción noética de la intención y su cumplimiento según operaciones de epojé, elucidación, proyección de horizonte fenomenológico (retención, presencia, protención, apareamiento conceptual, escorzo, metasemia - término de Ortega y Gasset en el concepto de su Nueva Lingüística, anterior a los años 50-, expectativa intencional y cumplimiento objetivo, etc.) y otras funciones específicas del proceso gnoseológico de la forma noética y sus categorías. La unidad concordante de experiencia posible, expresión de Husserl, ya fundamenta los fenómenos de cohesión y coherencia, así como los escenarios de modelos cognitivos y sus ideaciones correspondientes.

Decimos todo esto en atención al artículo de J. Edson Rodríguez Leite sobre el fondo socio-interaccional, cognitivo y constructivo «del conocimiento y significación pública del mundo" (95-110). La categorización y construcción de sentido, si es verdad que se construye, ya responden a una experiencia prelativa que funda el espacio social a su vez fundador de este lenguaje así reducido a convención mutua, por más que tales teorías quieran explicarlo con fundamento. Los esquemas ya están rematizados cuando se constituyen. No hace falta otorgarles sentido, pues son ellos los que nos lo dan a nosotros formándolos y formándose.

El principio de composicionalidad resaltado por los positivistas desde G. Frege para decimos que toda forma o término halla su sentido en relación con el compuesto que la integra es básico en el análisis gramatical de la hermenéutica. El compuesto cifra el horizonte de aplicaciones del formante. Pero esto ya lo suponían Aristóteles y D. de Tracia. El logos, nos recuerda en esta revista Enrique G. Murachco, no está referido al texto escrito de la gramática, sino al decir o enunciado: el logos apofántico. Incluye ello, por tanto, esta declaración, aunque se trate de un texto ya escrito, que, al leerlo, se activa de nuevo, y la primera parte de la técnica gramatical es precisamente la lectura guiada por una entonación precisa. El tono adecuado nos da, como en música, la nota dicente, que en realidad ya dispone el modo básico de enunciación y comprensión del enunciado. El compuesto significativo o «syntheton semantikón» de Aristóteles incluye al sujeto como marca acopla- 
da al tema verbal, de tal modo que el tema cifra en todo nombre un dominio virtual de posibles cadencias o casos para el sustantivo y flexiones para el verbo, según la función determinada en el conjunto locutivo por la relación interna del sujeto y el verbo. $T(R) X$ sería la fórmula básica, cabe decir, para entender todo desarrollo de acción lingüística: el tema denomina un conjunto de acciones mentales previas cuya rematización es el logos apo-fántico o enunciado. Si el nombre no implica por sí mismo función, la instancia. La ptôsis o caso, la pro-thesis o pre-posición, son apéndices de la relación interna del nombre con el verbo, prolongaciones de éste en búsqueda de nombre o adjuntos suyos modales que luego fijan pre-posiciones, nos recuerda Enrique G. Muraschco al comentar la gramática de D. de Tracia.

Bajo tal aspecto, la gramática y lingüística generativa o cognitiva tampoco añaden nada nuevo a ese núcleo de implicaciones rematizadas, pues el eje sujeto-objeto es sólo polaridad remática de la situación gnoseológica que el objeto supone en cuanto presentado a un supuesto cognoscente. A la técnica gramatical la prelata una relación de objetividad cognoscitiva. El sujeto también está inmerso en una relación objetivante. Sujeta la acción que vive, realiza o contempla. El compuesto significativo remite a sus elementos integrados y los expande luego, si es preciso, hacia otros posibles en consonancia argumental con ellos. Esa relación de objetividad que atañe al sujeto sería, a nuestro entender, el fondo verbal del logos. Por eso el verbo le reserva una posición remática, explícita o implícita. Exprime, resume Enrique G. Murachco, el movimiento del sujeto o le atribuye un estado o cualidad. Es decir, depende de algo suyo, directa o colateralmente. El cómo de tal dependencia resulta aquí decisivo, pues el logos dice lo que acontece en el acto nominal de dar sentido a algo, sea un ente concreto, una acción, relación lógica, un estado de cosas o efecto de situación discursiva. $Y$ de nuevo nos remitimos a la fenomenología de base hermenéutica y, para nosotros, poética. Precisamos una gramática que revele el fondo ya no sólo generativo del logos, sino su fundamento trópico: el tropo del lenguaje. Saussure ya preveía, nos recuerdan los editores de los Écrits de Linguistique Générale (2002), S. Bouquet y R. Engler, una lingüística general de base semiológica que incluyera la retórica y la estilística, en la que el kenoma o unidad de engarce sería, con la negatividad diferenciada del formante, el principio epistemológico básico o de oposición intra-sistemática. Mucho ha dado que hablar esta negatividad que, a la postre, implica un instante positivo, por lo menos tético, de la di-ferencia. He aquí el talón de Aquiles de la lingüística, la marca -Merkmal - transicional, el corte discreto de la articulación, su margen cisorio y significante. Y esto sí es parte de la Ciencia del Lenguaje, como la denominó Amor Ruibal atribuyéndole, antes que Saussure, un carácter reflejo de base relacional y antepredicativa, precisamente trópica, fundada en un valor gnoseológico.

Bienvenida, pues, esta nueva revista, dos vértices, lengua y literatura, para un centro nuclear de largo alcance crítico, la Lingüística. Las implicaciones semánticas de la cantiga de Gil Pérez Conde dejan ver hasta qué punto el lenguaje replica in absentia lo que concebimos. Eso llamado metalengua es precisamente el fondo poético del lenguaje. La lengua «por dentro», no sólo por fuera, nos advierte el gramático griego. Un interior que descubre, añadimos, la paradoja del cognitivismo, pues, partiendo de una convención social de la lengua, recurre a metáforas que expliquen el proceso del lenguaje: meta, fuente, trayectoria, recipiente, compromiso de generalización y cognitivo, a la zaga del ontológico de Quine, etc. Primero convengamos en que la convención no es ya meta y 
fuente, un tropo inducido por el lenguaje. En él todo con-viene por ser función PRO-nombre del conocimiento.

Bienvenida aunque sea por la gama de observaciones y comentarios abiertos en esta propuesta. Lo único que les pediriamos a los colaboradores es que no den por explicados conceptos y teorías que son sólo, al menos de momento, puras descripciones con metáfora convencional de fondo. 